\title{
AMPUTATION AT THE KNEE-JOINT.
}

BY

\author{
GEORGE POLLOCK, F.R.C.S., \\ SURGEON TO ST. GEORGE'S HOSPITAI.
}

Received Oct. 21st.-Read Dec. 14th, 1869.

Amputation at the knee-joint is, perhaps, one of the very few subjects in practical surgery which has not already been brought to the notice of the Royal Medical and Chirurgical Society. Partly on this account, but especially on account of the importance of this operation, and of its comparatively recent revival, I have been anxious to place on record some few cases which have come under my care, and to relate the circumstances which have induced me to advocate and adopt the operation under certain conditions.

The subject has appeared to me well worthy the consideration of the Fellows of the Society, and I trust the facts herein related will justify this conclusion.

To trace the history of amputation at the knee-joint is not the object of this communication. Though the operation dates back to the 16th century, for a long period of time it was only occasionally advocated, but as frequently discarded. Nor can it be considered to have been more favorably enter- 
tained until within the last thirty or forty years, and then not by a large majority of the profession.

I venture to think some share of this apparent indifference, or even dislike to the operation, may be attributed to a positive want of experience, as to its advantages, or as to its results ; something, perhaps, may be due to a slight amount of prejudice against cutting through a large joint, and exposing an extensive surface of synovial membrane. For even at this present time amputation through the knee-joint cannot be considered in general favour. "The propriety of disarticulation at the knee-joint," writes Dr. Brinton, of Philadelphia, in 1867, " is still a mooted point in the practice of American Surgery. By a majority of surgeons the operation is, perhaps, regarded with suspicion. Many who in a given case of injury or disease would unhesitatingly amputate through the thigh, would in a similar case shrink from the performance of amputation at the knee-joint."

Since 1830, when Velpeau advocated its adoption, the operation has been slowly advancing in favour, and there has evidently been of late a more general desire to test its merits. It must be borne in mind that there are two different and distinct conditions involved in the proposal to remove the leg at the knee-joint: 1st. If there be disease of the joint with ulceration of the cartilages, amputation should be completed by the removal of the condyles of the femur and the articular surface of the patella, or the whole of that bone. 2nd. If there be no disease of the knee, but, from disease or accident, amputation of the leg be requisite, it should be completed by cutting through the joint without interference with the articular surfaces of the femur or patella.

Mr. Syme was one of the first in this country to encourage surgeons to view this operation as practical and comparatively safe. In 1845, he drew attention to the great mortality attendant on amputation through the thigh, and to the inconveniences of the stump which followed, often irritable, usually uncomfortable, occasionally much retracted and conical, and seldom or never capable of bearing any pressure 
on its extremity. Instead, therefore, of cutting through the thigh and the shaft of the femur, he amputated the limb at the joint, and removed subsequently a portion of the condyles. He justly observes that "the warrant for amputation (in diseases of the joint) lies in the bone," and not in the soft parts. By cutting through the condyles, instead of the shaft of the femur, he expected to avoid the risk of necrosis ; and by cutting through the cancellated structure of the condyles, he hoped to escape those dangers so commonly attendant on opening the medullary canal. He concluded that amputation through the condyles would ever prove less fatal than amputation through the shaft of the bone, and subsequent experience tends to prove the soundness of his views.

I must here remark that whatever can be urged in favour of amputation through the condyles, may be adduced as equally satisfactory, if not as stronger evidence in behalf of amputation through the joint, without removal of the articular cartilages of femur or patella; and I trust I am justified in advancing this opinion on the strength of certain facts which are presently to be considered.

Mr. Syme, at the time above alluded to, does not appear to have made any reference to-he certainly did not then advocate-the more simple operation to which I refer. Mr. Samuel Lane, of St. Mary's Hospital, was I believe one of the first surgeons in this country to perform this operation. In 1857 he successfully amputated through the knee-joint, without removing the articular cartilage, or the patella; and so satisfied was he with the operation that he has repeated it in several instances, and with very satisfactory results.

Mr. Lane has most kindly favoured me with particulars of all his cases, short details of which are appended in a table annexed to this communication.

Being myself strongly impressed with the conviction that amputation through the knee possessed many advantages not to be attained by the amputation of the limb higher up ; and suspecting that the mortality attendant on the one would not exceed that of the other operation, I decided to test its 
worth a few years ago. The first opportunity of doing so occurred in 1864, since which time seven other cases have been similarly treated by me. Their chief particulars are contained in the following short notices.

CaSE 1.-J. F-, æt. 51, admitted into St. George's Hospital November, 1864. He had been suffering for many months with epithelioma of the leg. There was a very large ulcerated surface in the middle of the front of the leg, deep at its centre, and there implicating the tibia; some glands in the groin were slightly enlarged. The patient was much reduced by constant and abundant discharge, most offensive in character. It became a question between amputation through the thigh or at the knee-joint; and as there appeared to be sufficient healthy skin to form a good flap in front, the latter operation was decided on.

The flap, to cover the greater portion of the stump, was made from the fore part of the leg; the posterior flap was cut rather short. The patella was not removed, nor was the articular cartilage of the femur interfered with.

A very slight portion of the margin of the anterior flap sloughed in a few days, but ample tissue was left to make a good cover for the end of the stump. The patient had no bad symptom after the operation, but progressed favorably from the first, and left the hospital in thirtyfive days, with an excellent stump, on which he could bear any reasonable amount of pressure.

CASE 2.-M. G-, æt. 55, was admitted into the hospital in a very low state of mind and body. She was a lunatic, and was suffering from elephantiasis of the foot and lower half of the leg, upon which were several large and deep ulcers discharging most freely. It was a question whether amputation would save life, though there was no prospect of recovery without it. It was decided that the limb should be removed, and $I$ amputated at the knee-joint in a manner similar to that in the first case. The patella and articular cartilage 
of the femur were not interfered with-very little blood was lost in the operation.

The patient appeared unconscious of the loss of her limb. It was impossible to keep her quiet, she knocked the stump about with perfect indifference, and was obliged to be constantly watched to prevent her getting out of bed. In this state she gradually sank and died on the third day after the operation. Her mental condition appeared to influence the result more than the operation, as she refused nourishment, never slept, and was never quiet.

CASE 3.-V. B-, was admitted into the hospital with dislocation of the foot outwards on the astragalus. There was very severe contusion of the soft parts surrounding the injury and much extravasation of blood. An attempt was at once made to reduce the dislocation, but as it proved unsuccessful, the achilles tendon and also that of the tibialis anticus muscle were divided, the latter being much stretched. These measures did not prove of any service, and all efforts at reduction failed.

The cause of this failure was afterwards explained by the position of the tendons of the posterior tibial and long flexor muscles, one having slipped in front, the other behind the prominent head of the astragalus. In a few days extensive suppuration took place, and the skin over the astragalus ulcerated. The patient was now removed from the hospital. The condition of the leg became daily worse. Suppuration had extended more than half way to the knee, and the skin as high as the joint was dusky red in colour. A few days subsequent to his removal, while I was dressing the leg assisted by Mr. Lattey, late house surgeon to St. George's Hospital, we observed arterial hæmorrhage from the wound over the astragalus. This so rapidly increased that we were obliged to apply a tourniquet at once; and in the course of the afternoon I amputated the leg. As suppuration had already extended three parts up the leg, I had no alternative but to remove it high up; but as the skin did not offer any encouragement to do so below the knee, I decided 
to amputate through the joint rather than above, for I was anxious to avoid cutting through bone, as there already existed signs of incipient pyæmia.

The patient bore the operation well, which was in every respect similar to those already described; the patella was not removed. A small portion of the anterior flap ulcerated, which, considering the condition of the integuments prior to the operation, was not unlooked for. But, though this rendered the healing of the wound somewhat tedious, the patient, when seen some months after, was able to bear any reasonable amount of weight on the extremity of the stump, and used his artificial leg without any inconvenience. During convalescence two very large abscesses formed, one in each thigh; apparently the result of absorption of pus previous to the amputation.

CASE 4.-E. L-, æt.29, was admitted with severe compound fracture of the leg, and extensive laceration of the soft parts. It became a question between amputation through the head of the tibia, the knee-joint, or through the thigh. I decided to operate through the joint, being of opinion that a better stump would be obtained than if the head of the tibia were cut through.

The operation differed in no respect from the previous ones. The patella and articular cartilage were not disturbed.

Phagedæna appeared in the wound a few days after the operation, and secondary hæmorrhage subsequently occurred. Some portion of the anterior flap was lost by sloughing, but ultimately the patient recovered and left the hospital with a good stump. Though the articular cartilage was exposed for many days during the continuance of phagedæna, no subsequent evil results were observed from this circumstance.

CASE 5.-W.S-, æt. 48, admitted with compound fracture of the leg, and subsequently attacked by sloughing and phagedæna of the wound. He was so much reduced by repeated attacks of hæmorrhage, that, though very weak and 
low, amputation appeared to offer the only prospect of saving life.

The soft tissues of the leg were generally much involved by suppuration and ulceration; still I hoped to be able to secure sufficient flap in front to cover the end of the femur, and therefore decided to remove the limb at the knee-joint. When, however, the leg was separated from the thigh, there was not sufficient skin to cover the condyles without an undue amount of traction on the edges of the flaps. It was, therefore, necessary to remove a portion of the condyles, and the patella was also dissected out. The flaps now readily met, and covered the end of the femur. The patient was not much exhausted by the operation. His subsequent progress was most satisfactory, and he left the hospital hearty and strong with an excellent stump.

CASE 6.-J.T-,æt.39, admitted in 1868, for long-continued chronic ulceration of foot, which had commenced in the toes, and had gradually spread to the foot, destroying all the soft and osseous tissues in its progress towards the ankle. The greater portion of the foot was gone, a pointed ulcerated extremity projected in front of the astragalus and os calcis. This ulcerated surface was excessively painful.

The integument and soft tissues around the ankle and three parts up the leg were thickened, œdematous, and had assumed the characteristic conditions of elephantiasis. The ulceration of the foot was slowly spreading, and threatened sooner or later to involve the structures of the ankle-joint. She was most willing to submit to the loss of the limb. Considering the condition of the soft tissues of the leg, I decided to operate at the knee. The operation was in every respect similar to the first two related, the patella was not removed, nor the cartilage of the femur interfered with.

A very thin line, about an inch and a half in length of the anterior flap, sloughed and readily separated; but beyond this all went well, and the patient recovered with an admirable stump. She was able to bear her whole weight on its extremity. 
CASE 7.-E. H-, admitted March, 1869, with ulceration of cartilages and partial dislocation backwards of the left tibia of three years' duration. She was a delicate-looking woman, and there was a suspicion of tubercular mischief in the apex of the right lung. Under these circumstances it was not deemed prudent to excise the joint, and consequently amputation was had recourse to through the knee.

The articular surfaces being diseased were removed with a portion of the condyles and the whole of the patella.

A small abscess formed in the part previously occupied by the patella and somewhat retarded recovery; but before the patient returned home in July, the stump had quite healed, was excellent in shape, and capable of bearing the weight of the body.

CASE 8.-B. E-, æt. 22, admitted with strumous disease of the knee. The joint was acutely painful and partially dislocated. There was suspicion of incipient tubercular mischief in the apices of both lungs. Under these circumstances it was decided to amputate through the joint rather than excise it. The articular surface of the femur was extensively ulcerated, and was removed with a portion of the condyles; and the patella was dissected out, as its cartilage was similarly affected. Severe hæmorrhage occurred a few hours after the patient returned to bed; the wound had to be exposed, and a large vessel was tied. He was greatly reduced by the loss of blood, and severe constitutional irritation soon followed. The flaps of the stump retracted to a remarkable extent; so much so that a week after the operation the end of the bone was perfectly exposed. By degrees, however, the sawn extremity of the femur became covered with granulations, and the edges of the flaps as cicatrisation advanced, gradually, but very slowly, approached each other. Several large abscesses which formed in the stump had their origin apparently in the cavity occasioned by the removal of the patella.

The patient gradually gained strength; and the stump had nearly healed, some four months after the operation, when 
he was removed to our convalescent hospital at Wimbledon. The wound which remained was healthy and cicatrising; nor was there any apparent disease of bone, notwithstanding the long-continued exposure of the end of the femur.

This patient was exceptionally slow in recovering; but when we take into consideration his extremely delicate condition prior to the operation, the subsequent loss of blood, the excessive retraction of flaps, the large abscesses and longcontinued profuse discharge, and the subsequent condition of the stump, I think I am justified in considering the case as one affording evidence favorable to amputation through the joint and condyles. I doubt if this patient would have survived under amputation of the thigh higher np, followed by a similar demand on the system.

In the foregoing recital of cases no selection has been made in order to place amputation at the knee-joint in a more favorable light than it deserves. All the cases which have been treated by me are here truthfully recorded.

It will be observed that, of the eight, seven cases recovered and one died. The fatal case was a most unfavorable one for any kind of treatment ; her death can hardly be attributed to the operation, nor can it be supposed that her end was hastened by it more than if the thigh had been removed in the usual manner. Cases $3,4,5$, and 8 were all seriously ill when operated on; and $I$ even venture to think, that similar satisfactory results would not have followed under similar circumstances had amputation through the shaft of the thigh bone been performed instead. And though the cases are far too few to justify any conclusions as to the merits of the operation through the joint, yet when added to the number of cases to which reference is hereafter made, I think it will be conceded that material evidence has been produced to justify an opinion favorable to its adoption.

Before entering into some particulars to which I wish to draw especial attention, it will be satisfactory to state what evidence $I$ have been able to procure as to the advantages or disadvantages of amputation through the knee-joint; and also to state how far its results will bear comparison with 
those of amputation through the shaft of the femur. Much of this evidence has been obtained through friends : to the following of whom $I$ am indebted for the kindness and readiness with which they responded to my wishes-viz., to Mr. Willett, Surgical Registrar of St. Bartholomew's Hospital, Mr. Samuel Lane, Mr. James Lane, Mr. Birkett, Mr. Curling, Mr. Cooper Forster, Mr. Henry Smith, of King's College Hospital, Mr. Campbell de Morgan, Mr. Moore, Mr. Sydney Jones, Mr. Durham, Mr. Little, and my colleague Mr. T. Holmes. The mention of these names will prove, if that were requisite, that my evidence is derived from unquestionable sources.

Mr. James Lane, in a letter dated July 1868, states that "the first amputation at the knee-joint at St. Mary's Hospital was in 1857. Since then we have had I should say about a dozen cases, the majority by my uncle (Mr. Samuel Lane), but some by Mr. Coulson, Mr. Ure, and myself. They have all or nearly all been with the long anterior flap, and the patella and the femoral condyles have not been interfered with. I do not at this moment remember any deaths. In all that $I$ have examined afterwards the patella remained distinctly moveable upon the condyles, but drawn up so as to be quite out of the way of the end of the stump."

Mr. Campbell de Morgan says, "I have amputated at the knee-joint three times. One died of pyæmia; one had partial sloughing of the flap, but there was enough left to form a fair covering. The remaining one did well. The one that died had sloughing of the leg from plugged artery after fracture; he was a bad subject and exhausted before the operation. The other two were for disease of the leg. The flap was in each a quadrangular anterior flap, with a short posterior one somewhat in Teale's style. I removed the patella in all my cases; I don't think I should do so again."

Mr. Henry Smith writes to me, "So far as my humble opinion is concerned I regard this operation with such especial favour that $I$ should always adopt it in suitable 
cases, in preference to amputation through the lower third of the thigh ; for it appears to be almost of necessity a less dangerous, and when the condyles of the femur are preserved the stump must be a better and more useful one."

Mr. Sydney Jones informs me that in the only case operated on in St. Thomas's Hospital (by Mr. Simon), "the flap was made from the front, the ultimate result was very good indeed; but the patient ran much risk from two or more severe attacks of secondary hæmorrhage."

Mr. L. S. Little writes to me, "I have had but one case of amputation at the knee-joint. The operation was done about a year after compound fracture of the leg, by long anterior, nearly rectangular flap, without patella. The result was a useful stump ; cicatrix behind."

Mr. Willett has kindly given me the following particulars from St. Bartholomew's Hospital, "There have been' several such operations within quite recent years. In every case that it was practicable the flap was raised from the front of the leg."

Mr. Birkett informs me that he has operated in two cases, and in both with large anterior flaps.

Mr. Cooper Forster says, "I herewith send you the report of the only case in which I have amputated at the kneejoint. The man has now a puckered cicatrix, about an inch in diameter, behind and between the condyles of the femur. He bears well on the end of the bone and has a very useful long limb. I am not sure that another time I should not leave the patella."

Mr. Moore writes to me, "I have removed a limb at the knee-joint for a female child, having extensive disease of the tibia. I saw her several years afterwards with a comfortable and useful limb. I took the whole flap from the anterior skin, particularly avoiding the muscle below the head of the tibia, which would have been deprived of its supply of blood from the anterior tibial artery. There was no sloughing, and the stump healed readily. I left the patella. I have since thought so highly of the plan as giving an anterior flap, and, what is of still greater advantage, a flap of skin; 
and as followed by rapid healing and an easy stump, that I have since done, or recommended it in about six cases. Of late $I$ have advised the removal of the patella, because I once saw suppuration above it, after it had been left in an excision of the knee; and also because in my first case the patella projected, and seemed as if it must be inconvenient. Nevertheless it was not so. I never saw trouble from opposing cartilage to the inner surface of the flap."

Mr. Durham, of Guy's Hospital, informs me, 1868, that he has operated twice at the knee-joint. In the first case the operation was performed for compound fracture of the leg with severe laceration and crushing of the soft parts. In front the laceration extended nearly to the knee. The anterior flap was carried as low as possible, but not low enough to render its length perfectly satisfactory. The patella was removed; the posterior flap was cut from within outwards, and was made long enough to compensate in great measure for the shortness of the anterior one. The patient left the hospital about two months and a half after the operation with the stump healed but tender. Six months after the cicatrix was firm and sound, but he could bear no pressure on the stump. The integuments were adherent to the bone. Flexion of the limb caused tension of the cicatrix. He could walk well with an ordinary wooden leg. In speaking of the second case, Mr. Durham says, "the only other case in which I amputated at the knee-joint has no claim to be recorded as an instance of the operation in question. I may, however, mention it to you, inasmuch as I think it illustrates the desirability of amputating through the joint, or else some little distance above it. The man had a hopelessly severe smash of the right leg. It seemed to me just possible that there might be enough integument uninjured to allow of amputation through the joint being satisfactorily completed. I accordingly made the attempt, operating very much as in the case of which the notes are enclosed. I found, however, that the flaps would not come nicely together, there was too much tension upon them, 
especially when the limb was ever so slightly flexed upon the pelvis. I, therefore, sawed through the condyles of the femur, about an inch and a half above the articular surface, but still through the broad part of the bone, cutting the bone so as to leave a rounded surface. The bone inflamed; suppuration extended up by the side of the bone, as well as in the medullary portion. The flap sloughed and retracted considerably. Subsequently I removed the lower portion of the bone, cutting through the femur about the middle. Ultimately the patient died. This case and the one of which I enclose particulars (already quoted) were the only cases that have come under my care out of a very large number requiring amputation, in which there has seemed the slightest inducement to try amputation through the joint with a fair chance of success. The injury has either been so low as to leave room for amputating below the knee, or has extended so high as to prevent the formation of satisfactory flaps without removing a portion of the femur. I have never seen a case of disease in which the circumstances appeared to me fairly to indicate amputation through the knee-joint. I have no doubt whatever in appropriate cases the operation is an excellent one; and if such cases should occur to me, I should certainly practise it. But $I$ think the appropriate cases must be rare in civil practice. I may perhaps add that the instrument maker we employ unhesitatingly condemns all stumps he has yet seen."

Mr. Holmes informs me that he has operated four times. "Two proved fatal, one of epithelioma of the foot and leg, who died, however, less from the operation than from preexisting disease, being a man of advanced age and broken constitution; the other a case of injury : a lad about fifteen years of age, who died from pyæmia. The other two recovered. One was a child. The remaining case was a tailor who recovered with an excellent stump, and is, I understand, an active leader in Reform processions, Hyde-park rows, and the like."

Since this letter was written Mr. Holmes has operated on 
two other cases, in both of which the condyles were removed; and in one the patella ; in the other only the articular surface of the patella. The first died in a few days after the operation from pyæmia. The second recovered with a good stump."

Such are the opinions of men who have had recent experience of this operation. I leave their evidence to speak for itself. The conclusions to me are most satisfactory. The information obtained through these and other sources enables me to place on record the results of forty-eight cases of amputation at the knee, all of which have occurred in England; and all within a comparatively recent period. Some few have been previously noticed, but the greater number, I believe, have never before been published or made use of for purposes of comparison. In either case they are equally valuable for the object in view, as they afford us the opportunity of testing their results with those, already known, of amputation through the thigh.

These forty-eight cases are arranged in the table $A$ appended to this communication; on reference to which it will be seen that of this number thirteen were fatal and thirty-five recovered. A series of forty-five cases, all of which occurred in America and reported by Dr. Brinton, ${ }^{1}$ surgeon to St. Joseph's Hospital, Philadelphia, are placed in table B ; on reference to which it will be found that of these, thirteen were fatal, and thirty-two recovered.

If the total results of the cases collected in both tables be taken; it will be found that of 93 cases, 26 died and 67 recovered. I think it desirable to mention with respect to these 93 cases, that, although they are all instances of amputation at the knee-joint, in several the articular cartilage, condyles, and patella were removed. My impression is that the removal of articular cartilage, \&c., rather augments than diminishes the danger of amputation through the joint. It is only reasonable to suppose that a cut surface of bone, exposed to the action of pus in a wound, would render the patient more liable to evil consequences than if bone and

1 'American Journal of Medical Sciences,' April, 1868. 
cartilage were left intact. If this be so the fact of these cases being included in the tables should place the success of simple amputation at the knee-joint without removal of cartilage, \&c., in a still more favorable light than the results of the whole of these cases would apparently justify.

The total results give a more favorable percentage of recoveries than do the cases referred to by Mr. James Lane. ${ }^{1}$ Of 60 cases collected by him; 21 died and 39 recovered. He speaks of this as a high rate of mortality, and accounts for it by saying, "out of these 60 cases, 7 occurred in the Crimea; of which 4 died : hence a rather higher rate of death."

The results of the cases collected in tables A and B contrast favorably with the published statistics of amputation through the thigh ; and as a test I have selected those published by Mr. James Lane, ${ }^{2}$ for I know not how to arrive at any more just conclusion than to take these as my standard of comparison.

The following are Mr. Lane's figures, viz. :

Amputation through the thigh: Total cases 1346. Fatal 560. Death rate $41 \cdot 60$.

Amputation through the knee-joint: Total cases 60 . Fatal 21. Death rate $35 \cdot 0$.

The results of Tables A and B :

Amputation through the knee-joint: Total cases 93. Fatal 26. Death rate 27.97.

If these figures are to be any guide, or if the results of the tabulated cases alone justify any conclusion being arrived at, it must be admitted that the death rate after amputation through the joint is less than that after amputation through the thigh. Mr. Syme, in writing on the comparative safety of the operation, says, "It is upon this ground that I wish to found the operation, and therefore I have said nothing of some other advantages which might be mentioned."

1 Cooper's 'Surgical Dictionary,' new ed., Article “Amputation."

2 lbid. 
I should not do justice to our professional brethren in America did I omit to state that much credit is due to them for the steady perseverance with which amputation through the knee has been tested in that country, and for the records they have given us of the results.

Dr. Stephen Smith, 1 in 1852, drew attention to the subject in an interesting paper, in which he mentions that as early as 1824, Dr. Nathan Smith, of New Haven, performed for the first time in America the operation of amputation through the knee-joint, and that the result was successful.

The observations of Dr. Markoe, ${ }^{2}$ of New York, published in 1856, are strongly in favour of this operation. He reports the results of eighteen cases.

Still more recently Dr. Brinton, ${ }^{3}$ of Philadelphia, in a very able article, has recorded the particulars of several unpublished cases, all of which I have placed, for the sake of comparison, in table $B$.

Dr. Brinton is favorable to the operation: he says, "in general terms it may be stated that the operation can be resorted to with propriety in many of those cases of injury and disease, which have hitherto demanded amputation through the lower third of the thigh, provided the integuments of the knee are sufficiently healthy to furnish materials for flaps; and provided also that the condyles of the femur are not involved to too great an extent."

Dr. Gross, ${ }^{4}$ in writing about the operation, says, "Much has been argued in commendation of it, and, if we may judge from the cases which have occurred in the hands of American and European surgeons, it is reasonable to infer that it will soon come into general favour." He approves of the patella being left, as it serves to fill up the gap between the condyles.

The following evidence from the War Department of the

1 'New York Journal of Medical Sciences,' Nov., 1852.

2 'New York Journal of Medicine,' Jan., 1856.

3 'American Jeurnal of Medical Sciences,' April, 1868.

4 Gross' 'Surgery,' vol. ii, p. 1086. 
United States is also satisfactory. " "This operation has found numerous advocates during the war, and has been frequently performed. The returns to October, 1864, give 132 cases, of which 52 recovered and 64 died.

"In 6 cases amputation of the thigh was subsequently performed, with 3 recoveries and 3 deaths. In 10 cases the result is undetermined."

"These figures are encouraging, and if we look at the primary operations alone, the result is still more gratifying."

"Of 49 cases of primary amputation at the knee-joint 31 recovered, and 16 died; while two underwent re-amputation; of whom one recovered, and one, a tuberculous subject, died. This gives a percentage of mortality in primary amputations at the knee-joint of 34.9 . The mortality of primary amputation at the lower third of the thigh is much larger than this; indeed, it has been already indisputably proved by the Crimean statistics, and by M. Malgaigne, that the mortality in amputation augments in exact proportion as the incisions approach the trunk."

"The objection to amputation at the knee-joint, that the resulting stump is ill-adaped to the use of an artificial limb, is set at rest by the results obtained by Hudson and other manufacturers, who distinctly declare that the stumps from the operations at the knee-joint give a base of support far better than any possibly to be gained in thigh stumps. It is well known that $M$. Legouest emphatically pronounces the disarticulation at the knee ' une mauvaise opération, plùs grave que l'amputation de la cuisse dans la continuité et qui doit être rejetée de la pratique ;' basing this assertion on the Crimean returns; but it is probable that the more extended experience of the late war will lead surgeons to share the convictions of Macleod, Baudens, and Malgaigne, that this operation is altogether preferable to amputation at the lower third of the thigh."

Mons. Malgaigne considers amputation at the knee-joint

1 'Circular,' No. 6, p: 47, issued by War Department, Washington, Nov., 1865.

VOL. LIII. 
to have been too lightly condemned, and that it merits a decided preference over amputation in the continuity of the thigh.

Mons. Baudens ${ }^{1}$ says that the opinion of all the principal surgeons of the French Army in the Crimea was, that amputation at the knee should be preferred to that of the thigh in all cases in which it is impossible to amputate through the upper part of the leg.

In 1864 Mr. Carden, of Worcester, published the results of his experience of amputations through the condyles, with a long flap of skin taken from the front of the leg. Long dissatisfied with the faulty stumps produced by the usual method of amputation through the muscles of the thigh, either by the circular or double flap operation, he writes, "I determined to try the method of amputation by a single flap of skin, and I have been so well satisfied with the results, that I have never since that time used any other."2 In thirty-one cases recorded by him, only five deaths occurred.

I think it will be sufficient, and to me it is satisfactory, to conclude the evidence in favour of this operation by referring to Sir W. Fergusson's observations on the subject. In the last edition of his work ${ }^{3}$ he speaks highly of Mr. Syme's proposal to amputate through the condyles of the femur; and adds in reference to the result of one case that " without exception, I deem the stump equal to any I have ever made in the thigh."

In his lectures on the progress of anatomy and surgery, in speaking of the advantages of the operation, he says, "More than twenty years ago I had satisfied myself on that score, and had it not been that I fancied I had struck a richer vein in surgery by the revival of excision of the knee, I am certain that most of those cases which I referred to in my lectures on this operation last season, would have been brought before you now as illustrations of amputation at the knee."'

1 'Comptes Rendus,' t. xli, p. 1079, 1855.

2 'British Medical Journal,' April, 1864, p. 416.

3 . Practical Surgery,' 1857, p. 496. 
It remains to me to make a few remarks on the operation itself, on the advantages of the stump secured by the operation, and on the form of artificial leg adapted to this stump.

In amputating a limb in a case in which the joint is sound, and the disease or injury is confined to the leg, I much prefer a long anterior flap. In this respect I believe most surgeons of experience are now agreed. Mr. Syme at first advocated a long flap to be taken from the back of the leg, but he changed his views, in this respect, after the publication of Mr. Carden's paper, and gave just credit to this eminent surgeon for having practically and successfully demonstrated the advantages of the long anterior flap.

The anterior flap should be sufficiently long and broad to cover the whole of the exposed articular surface of the femur. It should consist entirely of integument taken from the sides and front of the knee and tibia; no muscle should be included in it. Its base should be two thirds of the circumference of the limb; that of the posterior flap should make up the remaining third. In lacerated wounds of the leg, the surgeon must of course make his flap as he best can.

A long anterior flap possesses many advantages over a long posterior one. When adapted to the surface of the condyles, it permits the ready escape of the discharge from the stump, and when the latter is healed, forms a cushion of skin over the end capable of bearing any reasonable amount of weight, for this skin has from childhood been subject to friction and pressure. It contains no large blood-vessels, seldom requires the application of a ligature, and is traversed by no large nerves. It enables the surgeon to cut from behind, muscles, tendons, blood-vessels, and nerves, at right angles with the limb. It ensures the large nerves from being implicated in the cicatrix, as their ends are drawn up behind the condyles and out of harm's way. It favours a cicatrix at the posterior aspect of the stump, one not liable, therefore, to be fretted by the contact of an artificial support.

As the long anterior flap consists of integument alone, 
it has a tendency to ulcerate or slough at its extremity soon after the operation. I have observed this occur to a slight extent more than once. Mr. Birkett informed me that he made a long anterior flap in a case in which the limb was very large and fat; whilst the stump was being dressed, about three inches of the end of the flap was observed to change colour, and in a short time was of a dull purplish hue. The following day the upper flap became gangrenous to that extent.

To avoid this chance of ulceration or sloughing it is best to commence the incision for the anterior flap far back on the side of the joint; and after carrying it downwards and across the leg in front, to terminate it equally far back on the opposite side of the joint. I make it a rule to feel for the interval between the edges of the condyle and head of tibia, and to commence my incision at that point, and immediately behind the edge of the hamstring muscle, as it crosses that space. I take especial care never to commence my incision higher than the margin of the condyle. The incision should be carried perpendicularly downwards on the side of the leg till nearly five inches below the lower edge of the patella, then gradually brought across the front of the leg, and when crossing the tibia should be quite five inches below the patella; then carried up the inner side to a point corresponding exactly to that from which the incision commenced. If the knife is introduced higher up than at the point mentioned, the incision will not only be longer than requisite, but the blood-vessels on each side, and which pass from behind forwards, are unnecessarily divided at the base of the flap, and consequently its arterial supply is diminished by so much, and sloughing or ulceration of some portion of its extremity rendered more probable. If the flap be made after the above rule, its base will be as broad as it can conveniently be made, and will consequently be better able to maintain the vitality of its whole surface than if the flap were narrow as well as long. ${ }^{1}$

1 These directions only apply to cases in which the condyles and patella are 
I usually make the posterior flap by cutting from without inwards; it should not be too short, and should consist merely of integument. It cannot be too strongly pointed out that in this operation rather more flap than is absolutely requisite is no evil ; the mistake to guard against is not having enough, a mistake apt to occur in the hands of one not familiar with the operation, for it usually happens that directly the deeper tissues behind the joint are divided, the posterior flap is drawn upwards, and sometimes to a considerable and inconvenient extent. As soon as the flaps are completed all the structures round the joint should be divided at a right angle with the limb.

The observations respecting the length of the anterior flap apply especially to the cases in which the condyles are not removed. In these cases the flap must necessarily be longer than when the condyles are sawn through, and the patella removed; in the former there is a tendency to ulceration or sloughing at the extremity of the flap; and hence the necessity of every precaution to guard against such an occurrence.

If there be disease of the knee-joint, the condyles should be partially removed and also the articular surface of the patella, after the leg is separated from the femur; and the long anterior flap in this case may be shorter by an inch or more. If the joint be healthy, it is best not to interfere with either condyles or patella. I have never found any inconvenience result from the patella when left after this operation, and, as already observed by others as well as myself, it serves to fill the depression between the condyles, and adds a roundness to this portion of the stump. I am much impressed with the importance of not interfering with the patella if it is possible to avoid doing so. If its cartilage is diseased, it is best to remove its articular surface alone, but to leave its upper half, or more attached portion, undisturbed. If the entire patella be removed there is left in its place an irregular jagged cavity with a thin layer of skin to form the not removed. The incision for the anterior flap must extend higher when it is intended to remove the condyles. 
cover, while the cut edges of aponeurosis and ligaments form its walls; and when the anterior flap is drawn over the end of the femur and fixed to the posterior one, this cavity becomes the receptacle of fluid, which, in a few days, probably suppurates, and burrows upwards between the layers of muscle and fasciæ; often perforates the skin in front, and requires much time and attention, and often frequent incisions before the parts become sound. Such results in my experience are less liable to occur when the patella is not disturbed or interfered with, or when its articular surface is alone removed. This is best done with a pair of forceps especially constructed for the purpose at my suggestion by Mr. Blaise. The instrument consists of one concave semicircular blunt blade, claw-like, to receive the edge of one half of the patella; the other blade is a semicircular convex-cutting surface : with such an instrument the operator can easily and smoothly shave off as much of the articular face as he may desire. In amputation through a healthy joint I have seen no ill effects from the articular cartilage of femur and patella being left intact. Mr. Erichsen thinks it better to leave the patella in this operation, but to remove the cartilage from it as well as from the condyles. ${ }^{1}$ Mr. Butcher advocates the removal of the articular surfaces of the condyles, and is of opinion that the patella should always be removed. ${ }^{2}$ But it is not customary to remove the articular cartilage from the glenoid cavity after amputation at the shoulder-joint, or from the acetabulum after amputation at the hip, or from the head of the humerus when requisite to remove the scapula. It is equally unnecessary at the knee-joint. Months after the removal of the leg, and long after the wound has healed, I have found the patella partially moveable when its articular cartilage had not been interfered with. Mr. James Lane has made a similar observation. I have never experienced the least drawback after this operation when the articular cartilages have been left to be dealt with by nature. I have never seen it exfoliate, or retard the healing of the stump.

\footnotetext{
1 ' Erichsen's Surgery,' vol. i, p. 53.

2 ' Essays and Reports,' p. 454.
} 
The more I have compared the stumps secured by amputation at the knee, whether the condyles were removed or not, with those after the amputation through the shaft of the femur, the more satisfied $I$ have been that there is no comparison between the two in strength and facility for locomotion, in subsequent comfort and freedom from pain, and in capability to bear weight and endure exercise.

To adapt - a good, useful, and inexpensive artificial leg to such a stump is a matter of no difficulty. A cast of the stump of a recent case under my care, and a fac-simile of the artificial leg adapted to it, have been placed on the table. $\mathrm{I}$ have to express my thanks to $\mathrm{Mr}$. Blaise for carrying out my suggestions in the construction of the latter. It fits the stump most perfectly, offers a firm broad bearing surface for its extremity, and, by a very simple contrivance, may be fixed in a straight position when required for walking, or flexed when the patient sits.

In conclusion, I should observe that I do not wish to attach more importance to the operation of amputation through the knee-joint than it really deserves. I hope and believe I have brought forward sufficient evidence to induce surgeons more generally to test its merits, and if hereafter it should prove that a small percentage of life is gained by its more common adoption, the object of this communication will not have been unsuccessful. 
ON AMPUTATION AT THE KNEE-JOINT.

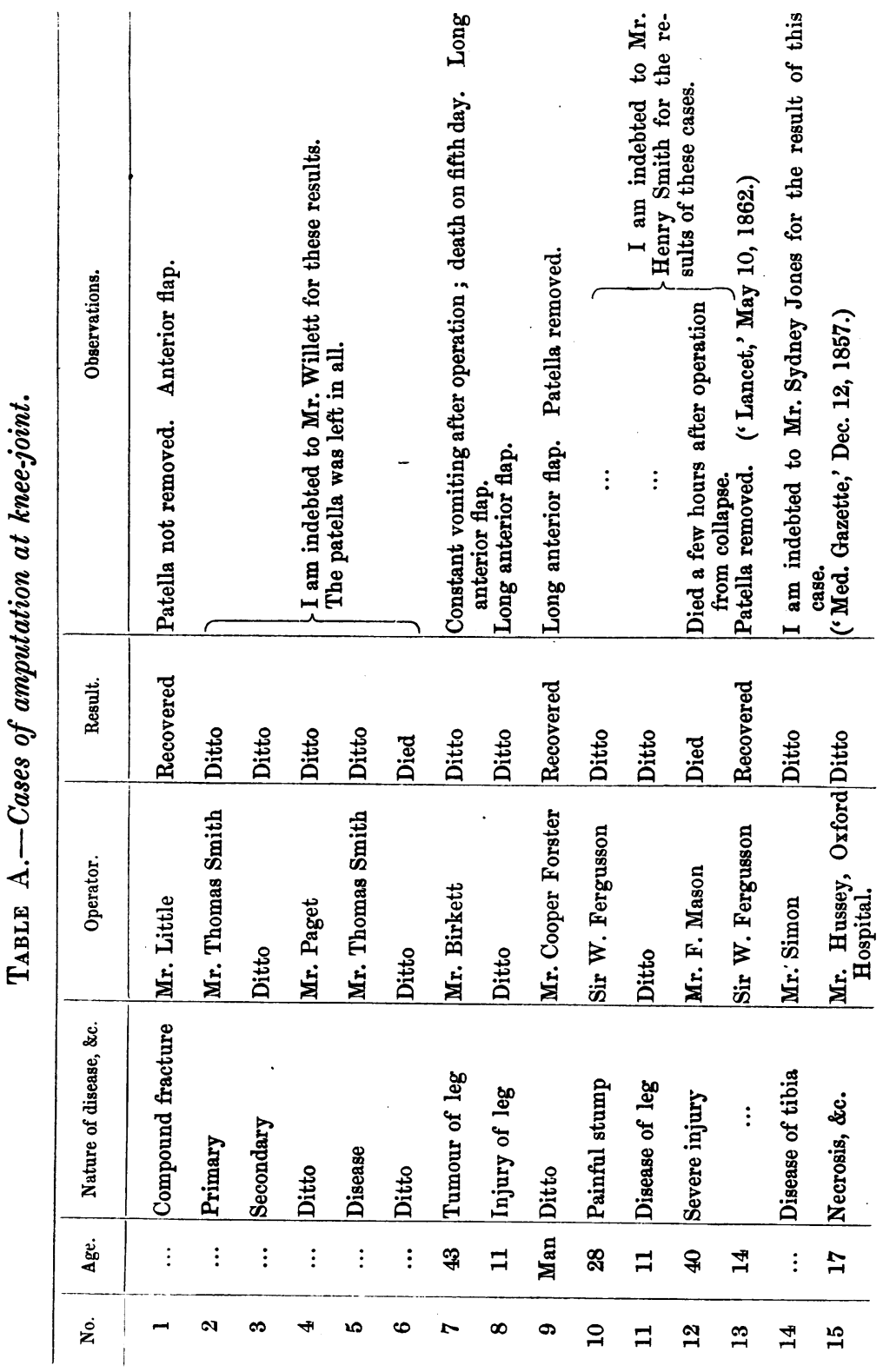




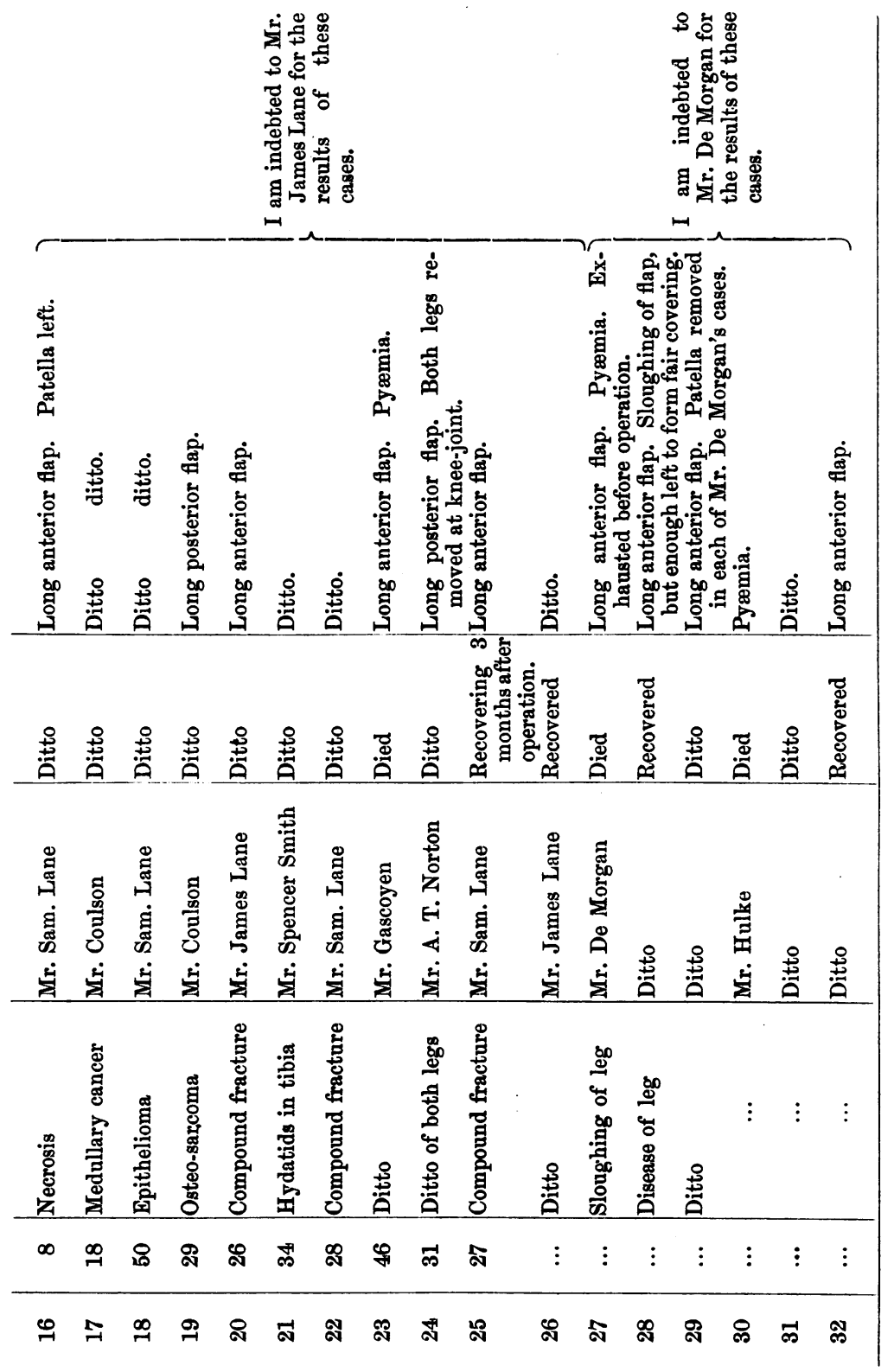




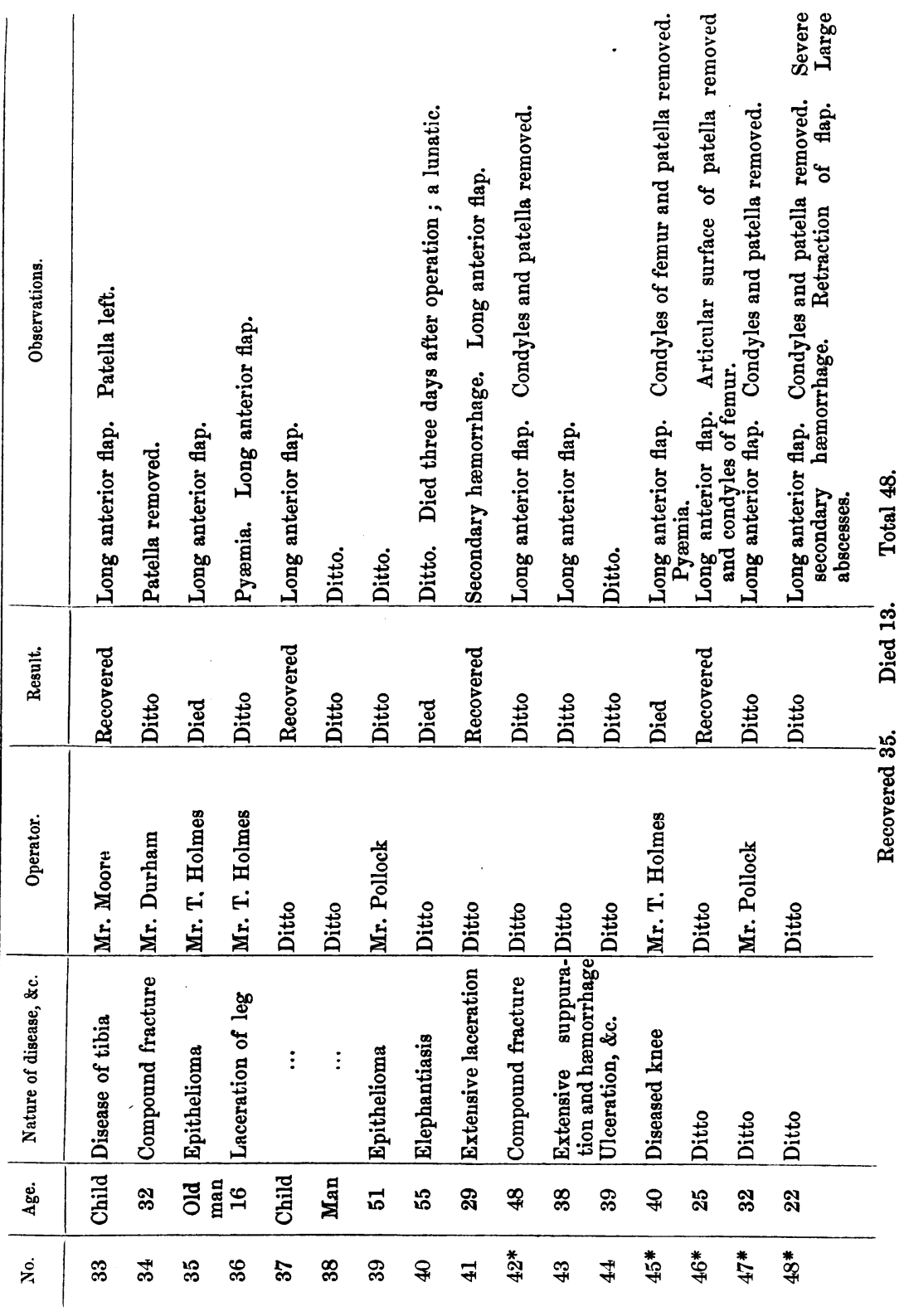


ON AMPUTATION AT THE KNEE-JOINT.

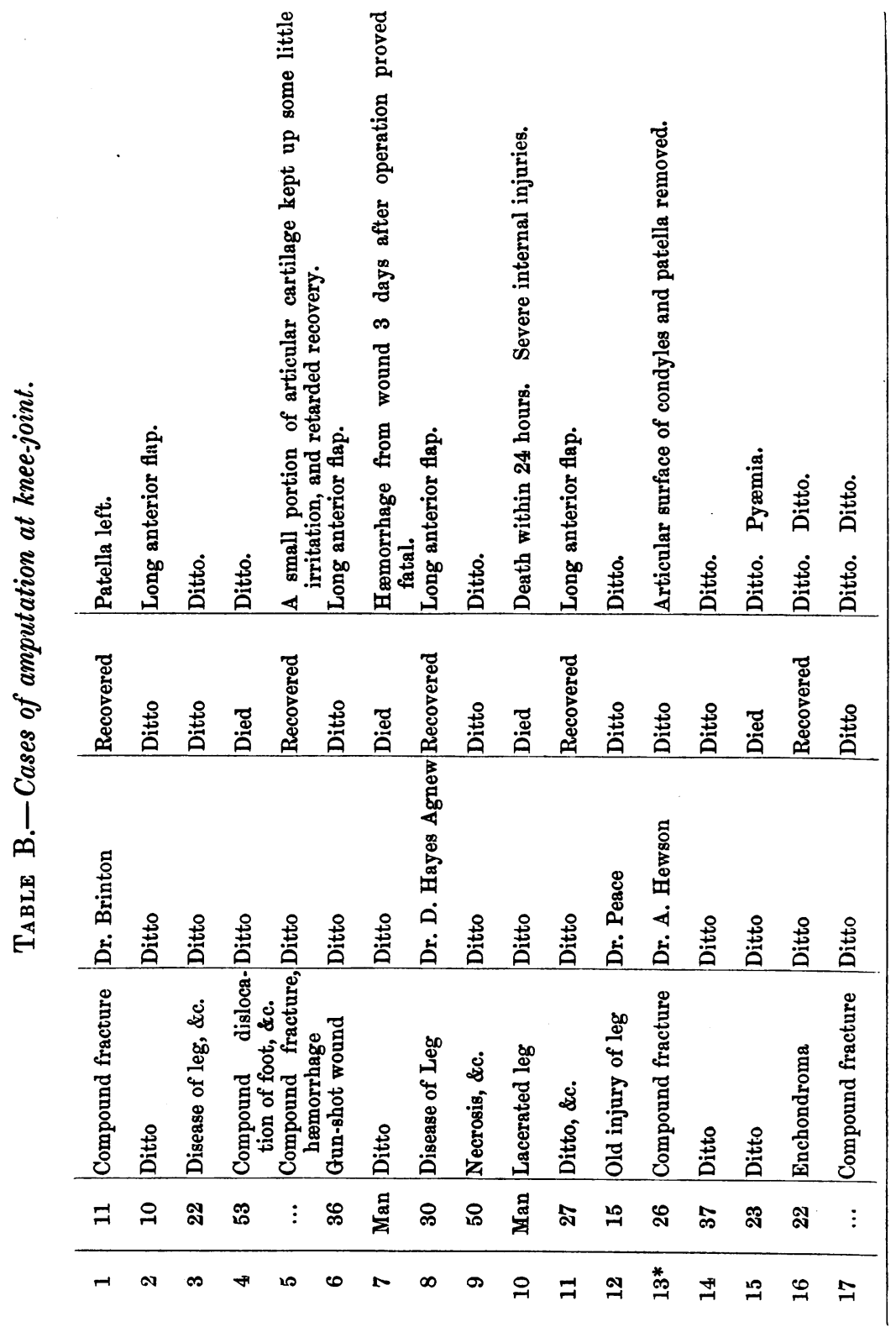




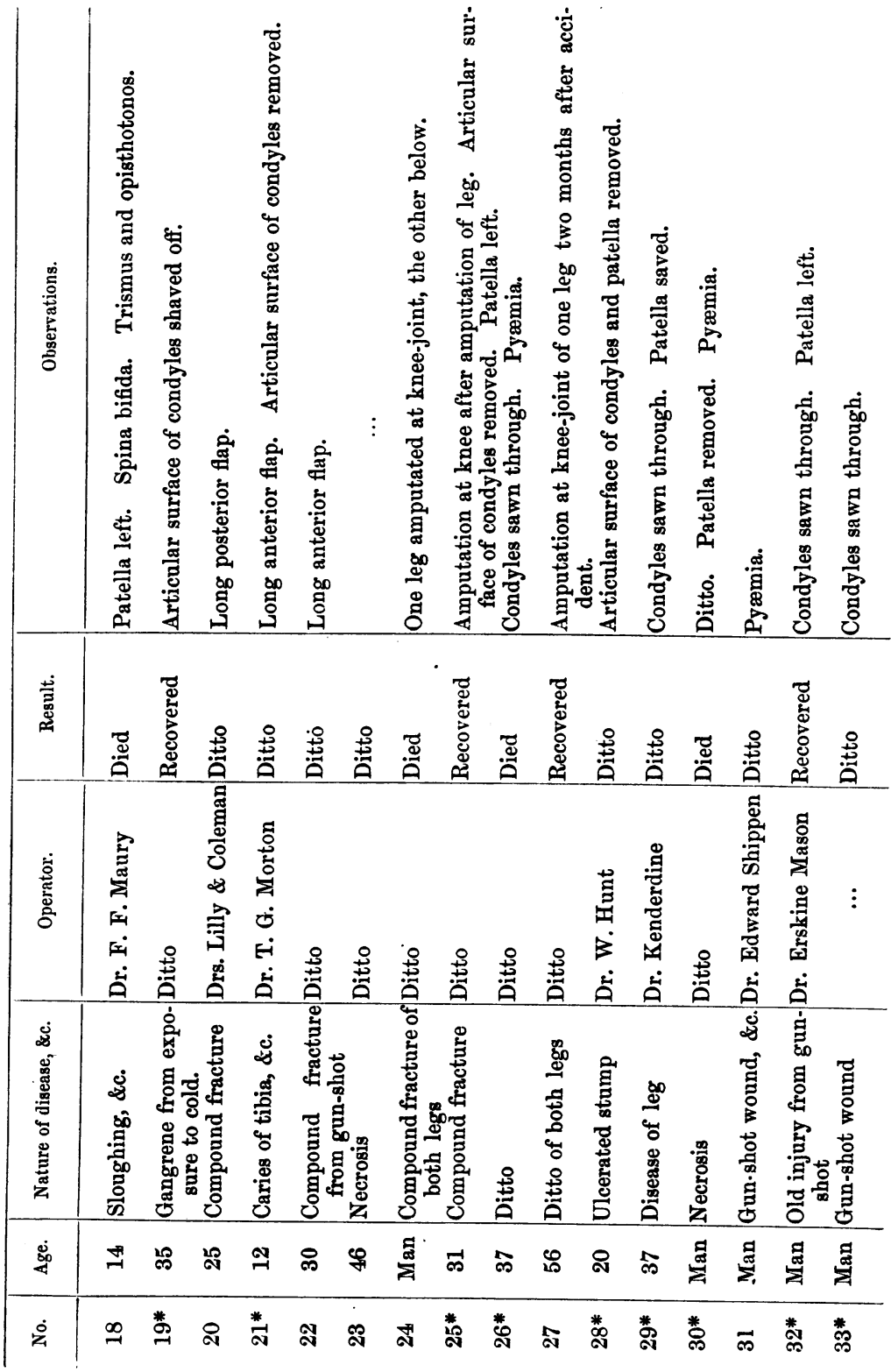


ON AMPUTATION AT THE KNEE-JOINT.

量

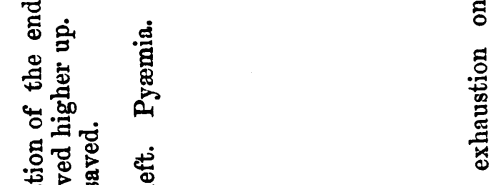

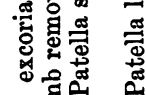

g. है

. 㟒然

密密宽

苛密

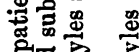

尝

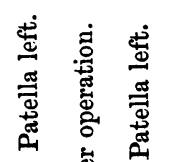

क्षि

马

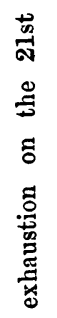

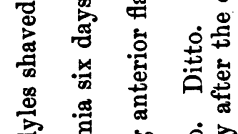

衰

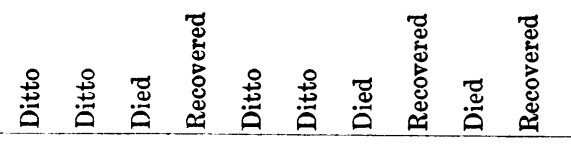

密

ค 饮

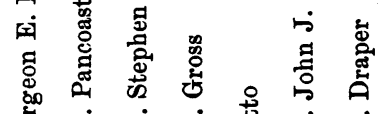

密

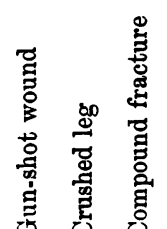

$$
\text { คे }
$$

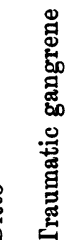

政

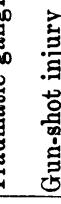

$\stackrel{3}{.5}$

(1)

ธี

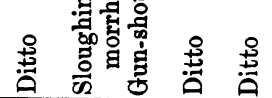

ส

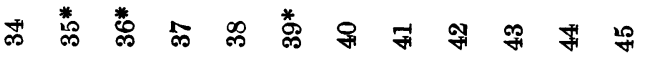

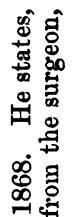

窟

4

is

.

绕

बढㅇㅇ

宽.

突

苋.

喼

言

要

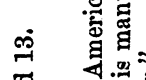

范

密

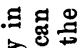

มี

要品

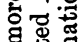

og

边语

$\Phi$

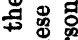

월

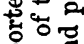

웅

o

西

施

됴

路

형을

突灵 